\title{
Parity and influence of abiotic factors on Anopheles in the Manso dam, State of Mato Grosso, Brazil
}

\author{
Ana Lúcia Maria Ribeiro[1], Rosina Djunko Miyazaki ${ }^{[2]}$, Jorge Senatore Vargas Rodrigues ${ }^{[1]}$ \\ and José Holanda Campelo Júnior ${ }^{[3]}$
}

[1]. Hospital Universitário Júlio Muller, Faculdade de Medicina, Universidade Federal de Mato Grosso, Cuiabá, MT. [2]. Instituto de Biociências, Universidade Federal de Mato Grosso, Cuiabá, MT. [3]. Departamento de Solos e Engenharia Rural, Faculdade de Agronomia e Medicina Veterinária, Universidade Federal de Mato Grosso, Cuiabá, MT.

\begin{abstract}
Introduction: This study examined the parity of Anopheles mosquitoes and the influence of abiotic factors on the distribution of these mosquitoes in the Manso dam, Mato Grosso, Brazil. Methods: The anophelines were captured using the Human Attraction Technique for $12 \mathrm{~h}$, while recording the temperature and relative humidity. Parity was determined by examining the conditions of the filaments. Results: Anopheles darlingi and Anopheles triannulatus accounted for $98.5 \%$ of the anophelines, with $88 \%$ of these being parous. Conclusions: Sudden variations in weather could be the cause of shifts from the total absence of mosquitoes to the appearance of females in abundance over a three-day period.
\end{abstract}

Keywords: Malaria. Temperature. Air humidity.

Currently, $99.5 \%$ of all cases of malaria transmission in Brazil are concentrated in the Legal Amazon Region, which has a fauna rich in anopheline mosquitoes. The State of Mato Grosso is responsible for $1.1 \%$ of the reports of this disease in the Legal Amazon Region, and this percentage has not changed since $2003^{1}$.

Anopheles darlingi is the main malaria vector in the Amazon region, and it is the one that benefits the most from humancaused changes to the natural environment ${ }^{2}$. The presence of this species in the region is increasing due to changes in the environment ${ }^{3}$, including the formation of reservoirs, that provide favorable conditions for the proliferation of this vector; thereby increasing the incidence of the disease and the effects on human health. Other factors that affect the development of anopheline mosquitoes are climate and environmental factors such as temperature, humidity, rainfall, and the vegetation around large bodies of water ${ }^{4}$.

Malaria has been cited as the most important disease associated with hydroelectric power plants and their reservoirs, which are considered favorable habitats for several species of Anopheles. The possibility of the return of malaria has become a real concern in the areas surrounding the Porto Primavera Dam, where there is a large settlement of people who are frequently in contact with anopheline mosquitoes ${ }^{5}$.

Address to: Dr. José Holanda Campelo Júnior. DSER/FAMEV/UFMT. Av. Fernando Correa da Costa 2367, Bairro Boa Esperança, 78060-900 Cuiabá, MT, Brasil.

Phone: 5565 3615-8647

e-mail: campelo@cpd.ufmt.br

Received 15 September 2011

Accepted 7 December 2011
In 2006, the first case of malaria was reported in the area influenced by the Manso Dam, at the time of the initial flooding to form the reservoir ${ }^{1}$.

The behavior of Anopheles darlingi regarding anthropophily, exophily, and even the nychthemeral rhythm, has shown regional and seasonal variation. In general, it is believed that this species has either one peak of hematophagic activity around midnight, or two peaks: one at dawn and the other at dusk, with uninterrupted activity throughout the night ${ }^{2}$.

The purpose of this study was to determine the parity and the influence of abiotic factors on the annual distribution of the Anopheles nychthemeral rhythm in the area influenced by the reservoir of the Manso Hydroelectric Plant in the State of Mato Grosso.

The area influenced by the Manso Hydroelectric Plant is located in the south-central region of Mato Grosso, approximately $96 \mathrm{~km}$ from the City of Cuiabá.

The samples were collected at the geographic coordinates $14^{\circ} 56^{\prime} 54.2^{\prime \prime} \mathrm{S} 55^{\circ} 47^{\prime} 57.0^{\prime \prime} \mathrm{W}$, at Marina Morro do Chapéu, in the City of Chapada dos Guimarães, located on the banks of the Manso reservoir.

The samples were collected quarterly, in June, September, and December 2005, and in March, June, and September 2006, at a location $50 \mathrm{~m}$ from the lake. The samples were collected during a 12-h period, beginning at 6:00pm and ending at 6:00am the next day, for three nights during a week, totaling $36 \mathrm{~h}$ of collection per quarter.

Each night, four individuals working in teams of two, worked three-hour shifts, capturing anopheline mosquitoes using the human landing technique for 12h (HLT12h) with the aid of a Castro sucking tube. This method, chosen for its simplicity and efficiency, requires a device consisting of an 
acrylic tube containing a fine screen on the bottom end, which connects to a latex hose, and a flashlight to illuminate the area of the body before the mosquito starts the process of hematophagy.

At the beginning of each hour of collection, the air temperature and humidity were measured using a digital thermometer/hygrometer, and later an hourly average was calculated for each factor.

The captured specimens were placed in 500-ml adapted plastic jars, which were duly labeled. The jars were replaced every hour. The Anopheles mosquitoes were fed using cotton balls dipped in a $10 \%$ solution of water and sugar, placed inside a Styrofoam box prepared as a humid chamber, and transported live to the Entomology Laboratory of the Medical School of the Federal University of Mato Grosso, Cuiabá, Brazil.

At the laboratory, the female specimens were anesthetized in tubes containing ethyl acetate and then identified to the species level ${ }^{2}$ with the aid of a stereoscopic microscope.

The anesthetized females were dissected to establish parity based on the condition of their filaments ${ }^{6,7}$.

A chi-square test was used to test for significance (at the $p=0.05$ level) regarding the relative numbers of nulliparous and parous females. The Mann-Whitney U test was used to compare the median number of parous females during each night, and the average number of parous females collected per hour.

The Wang and Engel ${ }^{7}$ model was used to analyze the effect of temperature and humidity on the number of insects captured.

After 17 twelve-hour periods and 204 total hours of sampling, 2,762 Anopheles of seven different species were captured. The majority of the anopheline mosquitoes were Anopheles darlingi $(65.5 \%)$, followed by An. triannulatus (33.1\%), An. lutzi (0.9\%), An. albitarsis (0.4\%), An. benarrochi (0.1\%), and An. lanei and An. mattogrossensis (0.04\%). An. darlingi and An. triannulatus, which are primary and secondary vectors, respectively, comprised $98.6 \%$ of the mosquitoes captured. Anopheles darlingi and An. triannulatus were present every quarter, and were most prevalent in March 2006, at the end of the region's most intense rainy period of the year.

The results of the quarterly captures, by time intervals, are listed in Table 1. Only during sunset (6:00 to 7:00pm) did $A n$. darlingi show significantly higher activity than during the other collection times, reaching 646 individuals in March 2006.

A total of 1,579 female mosquitoes were dissected, the majority of which $[1,377(88 \%)$ individuals] were parous females. A small number [187 (12\%)] were nulliparous females.

The number of parous females was significantly higher than the number of nulliparous females $(p=0.0009)$.

By applying the Mann-Whitney $U$ test to compare the median number of parous females captured per hour during each three-month period of capture, it was verified that the occurrence of females in March 2006 was significantly higher than during the other periods of collection. The second largest number of parous females, observed in June of the same year, was more than twenty times lower than the number obtained in March. The quantities obtained during other collection periods did not differ significantly from each other (Table 2).
TABLE 1 - Nychthemeral distribution of female Anopheles darlingi collected in quarterly samplings at Marina Morro do Chapéu in the area influence by Usina Hidrelétrica de Manso, State of Mato Grosso, Brazil, between June 2005 and September of 2006.

\begin{tabular}{|c|c|c|c|c|c|c|c|}
\hline \multirow[b]{3}{*}{ Day time } & \multicolumn{6}{|c|}{ Sampling date } & \multirow[b]{3}{*}{ Total } \\
\hline & \multicolumn{3}{|c|}{2005} & \multicolumn{3}{|c|}{2006} & \\
\hline & Jun & Sep & $\overline{\text { Dec }}$ & Mar & Jun & Sep & \\
\hline $06: 00$ to $07: 00 \mathrm{pm}$ & 17 & 13 & 3 & 646 & 45 & 1 & 726 \\
\hline $07: 00$ to $08: 00 \mathrm{pm}$ & 0 & 1 & 2 & 133 & 0 & 0 & 136 \\
\hline 08:00 to $09: 00 \mathrm{pm}$ & 0 & 0 & 0 & 156 & 0 & 0 & 156 \\
\hline $09: 00$ to $10: 00 \mathrm{pm}$ & 4 & 0 & 0 & 126 & 0 & 0 & 130 \\
\hline $10: 00$ to $11: 00 \mathrm{pm}$ & 2 & 0 & 0 & 66 & 0 & 0 & 6 \\
\hline $11: 00$ to $00: 00 \mathrm{pm}$ & 0 & 1 & 3 & 26 & 0 & 0 & 30 \\
\hline $00: 00$ to $01: 00 \mathrm{am}$ & 0 & 0 & 1 & 64 & 0 & 0 & 65 \\
\hline $01: 00$ to $02: 00 \mathrm{am}$ & 0 & 0 & 0 & 125 & 0 & 0 & 125 \\
\hline $02: 00$ to $03: 00 \mathrm{am}$ & 0 & 0 & 0 & 98 & 0 & 0 & 98 \\
\hline 03:00 to $04: 00 \mathrm{am}$ & 0 & 0 & 0 & 105 & 0 & 0 & 105 \\
\hline $04: 00$ to $05: 00 \mathrm{am}$ & 0 & 0 & 0 & 37 & 0 & 0 & 37 \\
\hline $05: 00$ to $06: 00 \mathrm{am}$ & 8 & 4 & 0 & 123 & 2 & 0 & 134 \\
\hline Total & 31 & 19 & 9 & 1,705 & 47 & 1 & 1,809 \\
\hline
\end{tabular}

Comparison of the median number of parous females captured per hour during each of the 17 sampling nights, using the Mann-Whitney U test, revealed several instances of significant differences between some of the nights within the same quarterly three-day period. As can be seen in Table 2, there was a significant difference between the number of parous females captured on the first and third nights of June 2005,

TABLE 2 - Mean number* of parous females of Anopheles darlingi collected each night and the total over all three nights, sampled every three months, at Marina Morro do Chapéu in the area influenced by Usina Hidrelétrica de Manso, State of Mato Grosso, Brazil, between June 2005 and September 2006.

\begin{tabular}{lrrrr}
\hline & \multicolumn{3}{c}{ Sampling night } \\
\cline { 2 - 4 } Sampling date & first & second & third & Mean \\
\hline June 2005 & $0.00 \mathrm{a}$ & $0.25 \mathrm{ab}$ & $1.67 \mathrm{~b}$ & $0.64 \mathrm{AB}$ \\
September 2005 & $0.00 \mathrm{a}$ & $0.83 \mathrm{~b}$ & $0.50 \mathrm{a}$ & $0.44 \mathrm{AB}$ \\
December 2005 & $0.33 \mathrm{a}$ & $0.42 \mathrm{a}$ & $0.00 \mathrm{a}$ & $0.25 \mathrm{~A}$ \\
March 2006 & $13.83 \mathrm{a}$ & $62.75 \mathrm{~b}$ & $31.25 \mathrm{~b}$ & $35.94 \mathrm{C}$ \\
June 2006 & $2.50 \mathrm{a}$ & $1.08 \mathrm{a}$ & $1.25 \mathrm{a}$ & $1.61 \mathrm{~B}$ \\
September 2006 & $0.00 \mathrm{a}$ & $0.00 \mathrm{a}$ & $* *$ & $0.00 \mathrm{~A}$ \\
\hline
\end{tabular}

*Numbers in the same row with the same lowercase letter and numbers in the same column with the same capital letter are not significant median differences, according to a Mann-Whitney test, with $\alpha=0.05$. **No sampling. 
and between the second night and the first and third nights in September 2005. In March 2006, the number of females obtained during the three nights was significantly higher than the numbers collected in all other quarters, although the values obtained for the first night were significantly lower than those obtained for the second and third nights. In December 2005, June 2006, and September 2006, there were no significant differences among the three nights with respect to the number of females collected.

The significant differences between the hourly values observed on different nights in the same week, as can be verified in Table 2, indicate that more care should be taken to avoid generalizations regarding the results obtained. Conditions affecting the favorability of capturing females may have varied significantly over a relatively short period of time, which would influence the data obtained. Therefore, based on the results obtained, it is not prudent to affirm that the abundance of the vector is linked to specific time periods during the year.

It is probable that some of the biotic and abiotic environmental variables that are subject to hourly differences accounted for the observed variation, and had a greater effect on the occurrence of females than variation over longer periods, such as dry and rainy seasons, seasons of the year, or even months of the year.

According to Forattini ${ }^{6,8}$, the hematophagic activity of $A n$. darlingi is crepuscular and nocturnal, and variation in the activity can depend on the location within Brazil, time of year, precipitation, genetic variability, and habits of the local human population.

Oliveira ${ }^{9}$ observed a similar pattern during quarterly sampling from 2000 to 2002 on the banks of the APM Manso Dam reservoir: a unimodal frequency distribution of hematophagy with significant incidences of Anopheles in the first hours after sunset.

Analysis of the air temperature and humidity recorded at each time and date of capture revealed that the number of females did not show a significant simple correlation with either of these two variables. However, an observation of the dispersion of the number of females based on these two variables seems to indicate that the number of females must be influenced by other biotic and abiotic factors in addition to these two variables.

It is probable that the several factors that influence the number of females captured can be described with a multiplicative model, as used by authors such as Wang and Engel ${ }^{8}$ and Yin et al. ${ }^{10}$. In this case, each one of the variables involved could be represented by a factor with values between 0 and 1 , which would represent a nonlinear relationship with the independent variable, and which would limit the maximum value of the dependent variable. Lardeux and Chefort ${ }^{11}$, López et al. ${ }^{12}$, and Boivin et al. ${ }^{13}$ obtained experimental results for the effect of temperature on the development of different insects that fell into this type of model. $\mathrm{Xu}^{14}$ reported similar results for fungi. Wang and Engel $^{6}$ called one such factor $\mathrm{f}(\mathrm{T})$ and used an optimal temperature and low and high temperature limits to estimate $\mathrm{f}(\mathrm{T})$.

In the case of this study, this relationship could be represented as in Figure 1A and Figure 1B, in which the points represent the number of parous females of An. darlingi observed, and,

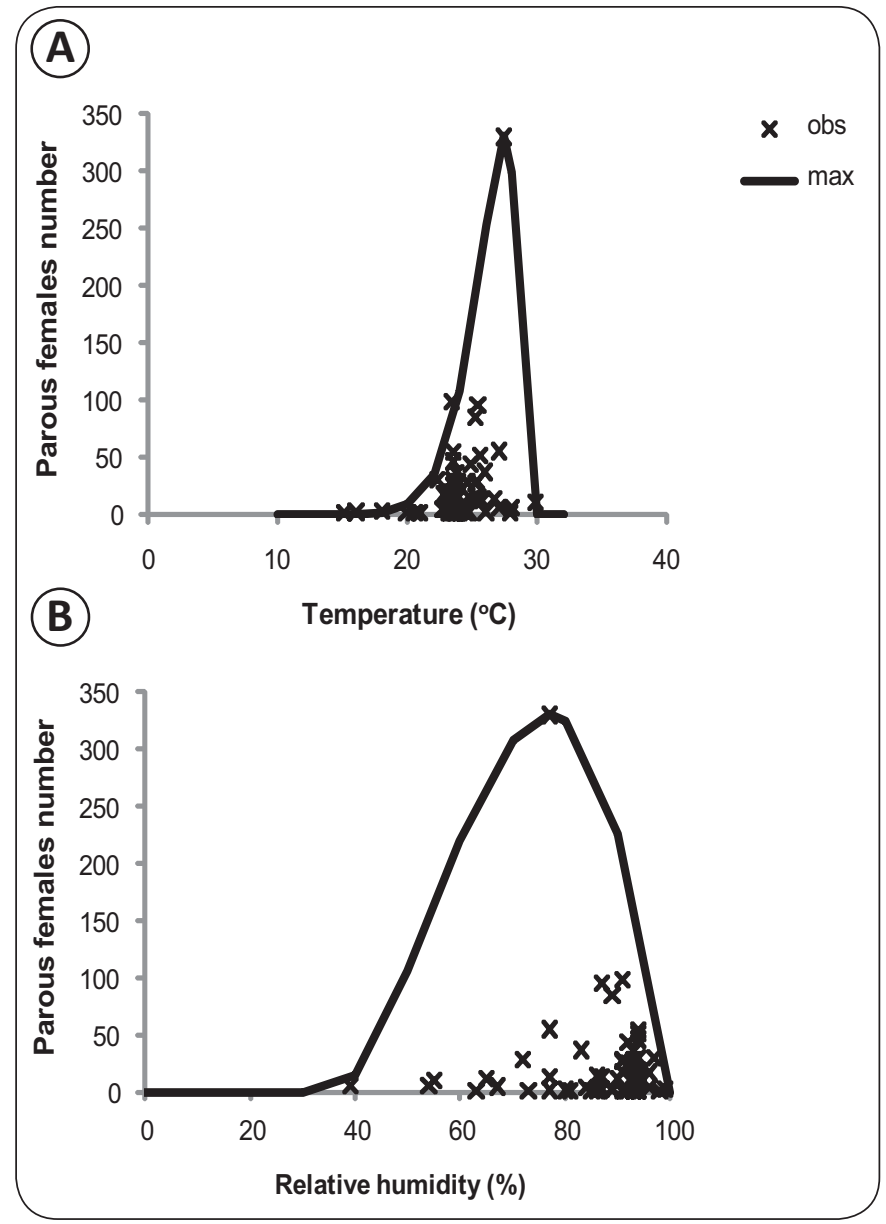

FIGURE 1 - Air temperature (A), and relative humidity (B) and number of parous females of Anopheles darlingi captured during quarterly samples in 2005 and 2006, in the area influenced by Usina Hidrelétrica de Manso, State of Mato Grosso, Brazil. Observed (obs) and maximum number (max), calculated by the function $\mathrm{f}(\mathrm{T})$.

respectively, the temperature and relative humidity measured during each 1-hour interval.

In Figure 1A, the line represents the maximum number of females calculated according to the function $\mathrm{f}(\mathrm{T})$, considering four parameters: the highest number of captured females; the minimum limit of $10^{\circ} \mathrm{C}$, below which there would be no females to captured; the maximum limit of $30^{\circ} \mathrm{C}$, above which there would be no females to captured; and the optimal temperature of $27.4^{\circ} \mathrm{C}$, when the number of females would be highest. Figure 1B shows the equivalent results, using $\mathrm{f}(\mathrm{RH})$, an adaptation of the function $\mathrm{f}(\mathrm{T})$ to the relative humidity of the air, defined using a minimum limit of $36 \%$, a maximum limit of $100 \%$, and an optimal humidity of $77 \%$.

In Figures 1A and 1B, the values observed are either on the line of maximum estimated values or below it. The values observed on the line of maximum estimated values using the Wang and Engel $^{6}$ model indicate that the horizontal axis variable is the one that restricts the presence of females at the time of capture. The values observed below the line of maximum estimated values using the Wang and Engel $^{6}$ model indicate that another variable, different from that expressed on 
the horizontal axis, imposes an even higher restriction on the appearance of females at the time of the capture. Several other phenomena, which depend on different environmental factors acting concomitantly, present similar behavior, a principle known as Liebig's Law of the Minimum, which was originally described by Justus von Liebig in the $19^{\text {th }}$ century ${ }^{15}$.

Therefore, sudden variations in weather variables could be the cause of the alternating total absence and high abundance of parous females of An. darlingi and An. triannulatus in the region within the space of three consecutive days, in every month of the year.

\section{CONFLICT OF INTEREST}

The authors declare that there is no conflict of interest.

\section{FINANCIAL SUPPORT}

\section{Fundação de Amparo à Pesquisa de Mato Grosso.}

\section{REFERENCES}

1. Ministério da Saúde. Malaria [Internet]. Brasília: Secretaria de Vigilância em Saúde 2010; [Cited 2010 October 22]. Available from: http//www.saude.gov. br/svs_malaria/.

2. Consoli RAGB, Oliveira RL. Principais mosquitos de importância sanitária no Brasil. $1^{\text {st }}$ ed. Rio de Janeiro: Fundação Oswaldo cruz; 1994.

3. Tadei WP, Mascarenhas BM, Podesta MG. Biologia de anofelinos amazônicos. VIII. Conhecimentos sobre a distribuição de espécies de Anopheles na região de Tucuruí-Marabá (Pará). Acta Amaz 1983; 13:103-140.
4. Tundisi JG. Impactos ecológicos da construção de represas: aspectos específicos e problemas de manejo. In: Tundisi JG, editor. Limmnologia e manejo de represas. Vol.1. São Paulo: Editora da USP; 1988. p. 1-75.

5. Gomes AC, Paula MB, Natal D, Gotlieb SLD. Ecologia de Anopheles (Nyssorhynchus) darlingi Root em área de implantação de empreendimento hidrelétrico, na divisa dos Estados do Mato Grosso do Sul e São Paulo. Rev Soc Bras Med Trop 2010; 43:272-276.

6. Detinova TS. Age grouping methods in Diptera of Medical importance. Geneva: World Health Organization; 1962.

7. Wang E, Engel T. Simulation of phenological development of wheat crops. Agric Sy London 1998; 58:1-24.

8. Forattini OP. Culicidologia Médica. Vol 2. São Paulo: Editora da Universidade de São Paulo; 2002.

9. Oliveira MS. Avaliação ecológica de anofelinos (Diptera: Culicidae) em áreas sob influência do Aproveitamento Múltiplo Manso, Mato Grosso, Brasil. [Masters Dissertation]. [Rio de Janeiro]: Instituto Oswaldo Cruz; 2004. 98p.

10. Yin X, Struick PC, Tang J, Qi C, Liu T. Model analysis of flowering phenology in recombinant inbred lines of barley. J Exp Bot 2005; 56:959-965.

11. Lardeux F, Chefort J. Temperature thresholds and statistical modeling of larval Wuchereria bancrofti (Filariidea: Onchocercidae) developmental rates. Parasitology 1997; 114:123-134.

12. López C, Sans A, Asin L, EizaGuirre M. Phenological model for Sesamia nonagrioides (Lepidoptera: Noctuidae). Entomol Soc Amer 2001; 30: 23-30.

13. Boivin T, Bouvier JC, Beslay D, Sauphanor B. Phenological segregation of insecticide resistance alleles in the codling moth Cydia pomonella (Lepidoptera: Tortricidae): a case study of ecological divergences associated with adaptive changes in populations. Genet Res 2003; 81:169-177.

14. Xu XM. On estimating non-linear response of fungal development under fluctuating temperatures. Plant Patology 1996; 45:163-171.

15. Von Liebig J. Die chemie in ihrer Anwendung auf Agrikultur und Physiologie. Veinegn: Braunschweig; 1840. 